\title{
REPRESENTAÇÕES E IDENTIDADE NA CIDADE NA PRIMEIRA METADE DO SÉCULO XX- OS SUBÚRBIOS CARIOCAS
}

Representations and identity in the city during the first half of the 20th Century- The Rio de Janeiro suburbs

\author{
Elizabeth Dezouzart Cardoso \\ Geógrafa com mestrado e doutorado em Geografia pela UFRJ e pela UFF; Pós- \\ doutorado no Prourb/UFRJ \\ e.dezouzart@uol.com.br
}

\section{Resumo}

Em trabalho anterior sobre segregação sócio-espacial e a "invenção da Zona Sul" carioca foi demonstrado por Cardoso (2009) como foram criadas representações positivas sobre a chamada Zona Sul carioca, tanto na imprensa de bairro como na grande imprensa e que as representações positivas e a identidade da Zona Sul se faziam pela diferença do chamado Subúrbio. Isso levou a empreender uma pesquisa sobre as representações sobre o Subúrbio, na imprensa de bairro desta área. Como pudemos verificar, as publicações do Subúrbio criaram e veicularam representações tanto positivas quanto negativas sobre a área em foco, cada uma "anulando" a outra.

\section{Palavras-chave}

Representações, subúrbio, Rio de Janeiro

\begin{abstract}
In a other work about social-spatial segregation and the "invention of the South Zone" in the city of Rio de Janeiro, it has been demonstrated how affirmative representations were created concerning the so-called South Zone of Rio de Janeiro, both in the local press and in the big press. It has also been demonstrated that the positive representations and the identity of the South Zone were made in contrast with and based on the difference of the so-called Suburb. This led us to carry a research about the representations of the Suburbs, in the local press of that area. We ascertained that the publications in the Suburbs created and transmitted both positive and negative representations about that area of, which "cancelled" each other.
\end{abstract}

Keyword

Representations, suburb, Rio de Janeiro 


\section{Introdução}

A área, desde os princípios do século XX, chamada de Subúrbio na cidade do Rio de Janeiro é aquela em torno dos caminhos das estradas de ferro, englobando dezenas de bairros onde se localizam as moradias da maior parte das camadas de baixa renda. Nesta cidade o termo subúrbio é muito forte e, como já apontavam Soares 1960), Pereira (2010) e Fernandes (1995-2011) ao contrário de outras cidades como, por exemplo São Paulo, ele está deslocado de seu sentido original, de área distante do centro e de pouca densidade de ocupação.

Em trabalho sobre segregação sócio-espacial e a invenção da Zona Sul carioca Cardoso (2009) demonstrou como foram criadas representações extremamente positivas sobre a chamada Zona Sul daquela cidade, área onde se concentra a maior parte das camadas de alta renda sendo que muitos de seus bairros são à beira-mar, tanto na imprensa de bairro como na grande imprensa. Foi demonstrado também que as representações positivas e a identidade da Zona Sul se faziam em contraste com e pela diferença ${ }^{1}$ do chamado Subúrbio que sempre aparecia com representações negativas na imprensa de bairro da Zona Sul. Essas representações se tornaram hegemônicas e têm um grande grau de permanência. Demonstramos ainda, naquele trabalho, como estas representações positivas sobre a Zona Sul permitiram cimentar um novo processo de auto-segregação das camadas de renda superior nesta área Sul a partir de princípios do século $X X$.

Estes resultados nos trouxeram a indagação sobre quais seriam as representações que a população do assim chamado Subúrbio teria criado sobre si mesma. Não teria "reagido" às representações e imagens negativas que se faziam deste lugar? Ou teriam se contraposto às representações que dele se faziam na Zona Sul e que se tornaram hegemônicas, entretanto, teriam perdido na luta sobre o poder de produzir representações uma vez que as que se tornaram hegemônicas vinham de uma população que estava no topo da pirâmide social, sendo assim, com mais capacidade de se fazer valer, arrastando para si a visão da grande imprensa que secundava a imprensa local daquela área?

Assim, como Cardoso (2009) aponta uma profusão de representações positivas sobre a Zona Sul surgindo de sua imprensa de bairro, quando grande parte desta área ainda tinha características típicas de subúrbio embora nunca tenha sido

\footnotetext{
${ }_{1}$ Sobre como a identidade se constrói a partir do estabelecimento da diferença veja-se Silva (2000) URBANA, V.6, no 9, ago-dez, 2014 - Dossiê: Dimensões Simbólicas das Intervenções Urbanas CIEC/UNICAMP
} 
assim chamada, nos questionamos sobre se e como foram criadas representações sobre o Subúrbio a partir de seus próprios moradores. Mais ainda, nos questionamos sobre quais representações foram estas e o porquê de não terem se tornado hegemônicas. Seria somente pelo fato de os jornais de circulação mais vasta repetirem a imprensa da Zona Sul, onde se encontrava a maioria da classe dominante e, provavelmente os próprios redatores dos jornais? Ou não foram criadas representações contra-hegemônicas sobre o Subúrbio?

Este conjunto de indagações nos levou a empreender uma pesquisa sobre as representações relativas ao Subúrbio, na imprensa de bairro desta área e na grande imprensa mais especificamente através da obra em crônicas de Lima Barreto. Pensamos, com este trabalho, contribuir para um melhor entendimento de como surgem e se estabelecem as principais representações sobre o espaço urbano carioca na primeira metade do século XX. As indagações acima colocadas, nos serviram de hipóteses.

\section{Referenciais teóricos}

A sociologia trata do tema das representações há várias décadas. O conceito de representação na sociologia francesa clássica na primeira metade do século XX teve forte influência de Durkheim e refere-se a "um conjunto de imagens, esquemas, modelos, símbolos e ideais veiculados por uma sociedade, particularmente no que diz respeito à figuração de um sistema do mundo ou de uma ordem de valores" (LOBO, 2000 p. 69).

Posteriormente, com o avanço do campo da psicologia social, surgiu o conceito de representações sociais, cunhado por Moscovici a partir do conceito de representações coletivas de Durheim. O conceito de representações sociais para Moscovici (2012, p. 21) é o seguinte:

Um sistema de valores, ideias e práticas,com dupla função: primeiro, estabelecer uma ordem que possibilitará às pessoas orientar-se em seu mundo material e social e controlá-lo; e, em segundo lugar, possibilitar que a comunicação seja possível entre os membros de uma comunidade, fornecendo-Ihes um código para nomear e classificar, sem ambiguidade, os vários aspectos de seu mundo e da sua história individual e social

Para Moscovici (2012 p. 20-21) as representações sociais se ligam à identidade, como se pode ver no trecho a seguir:

URBANA, V.6, no 9, ago-dez, 2014 - Dossiê: Dimensões Simbólicas das Intervenções Urbanas CIEC/UNICAMP 
(...) As representações sociais emergem não apenas como um modo de compreender um objeto particular mas também como uma forma em que o sujeito (indivíduo ou grupo) adquire uma capacidade de definição, uma função de identidade, que é uma das maneiras como as representações expressam um valor simbólico (...).

Outro importante autor a se referir à construção do conceito de representação é Lefebvre (1983). Logo no início de seu trabalho, Lefebvre (1983, p. 23) elabora uma definição de representação:

É às vezes um fato ou fenômeno de consciência, individual e social, que acompanha em uma sociedade determinada (e uma língua) tal palavra ou tal série de palavras, por uma parte, e por outra tal objeto ou constelação de objetos, outras vezes é uma coisa ou conjunto de coisas correspondente à relações que essas coisas encarnam contendo-as ou velando-as.

Um aspecto central da teoria sobre as representações de Lefebvre é o que trata de sua relação com a ideologia. Depois de fazer uma longa revisão da questão das representações e das ideologias em Marx, Lefebvre afirma que Marx e os marxistas muitas vezes substituem as representações por ideologias, não tratando das primeiras. Para Lefebvre, as representações não são nem verdadeiras nem falsas, podendo ser ambas ao mesmo tempo, e, por isso mesmo, aí reside sua força. De acordo com Lefebvre, as representações se distinguem das ideologias, dado que as primeiras podem conter as segundas. Esse é um ponto em que diverge da postura de Moscovici, para o qual um conjunto de representações pode conformar uma ideologia. Vejamos a citação a seguir: "as representações não podem passar somente por alterações do real e do verdadeiro, por máscaras e mascaradas, como na teoria habitual das 'ideologias'". (LEFEBVRE, 1983, p. 60).

Assim, as representações, para Lefebvre, podem ser falsas e verdadeiras a um só tempo (LEFEBVRE, 1983, P. 62). A complexa relação entre os conceitos de representações e de ideologia, por sua vez, é explicitada pelo autor na passagem a seguir:

Separar a ideologia, conceito crítico? Não. Deslocá-la pelo conceito de representação? Não, mas utilizar ambos os conceitos, reconsiderando, reconstruindo o de ideologia a partir de da teoria (crítica) das representações.(...) Rica e confusa, a representação envolve e inclui a ideologia, empobrecida, clarificada. A eficácia da abstração e da ideologia

URBANA, V.6, no 9, ago-dez, 2014 - Dossiê: Dimensões Simbólicas das Intervenções Urbanas CIEC/UNICAMP 
provém das representações que persistem nelas, mais ou menos reconhecíveis. (LEFEBVRE, 1983, p. 69) ${ }^{2}$.

Entretanto fomos encontrar no âmbito da história o autor com o qual vamos trabalhar. Nesta disciplina, encontramos um autor importante que tratou da questão das representações. Este foi Chartier (1981), que, no nosso entender, tratou das questões básicas que nos interessam para realizar este projeto: a relação de representações referidas a grupos diferentes e à identidade.

Preocupado em definir novos rumos para a história cultural, Chartier afirma que esta tem por principal objeto identificar o modo como em diferentes lugares e momentos uma determinada realidade social é construída, pensada e dada a ler. Um dos caminhos para isso é verificar as classificações, divisões e delimitações que organizam a apreensão do mundo social como categorias fundamentais de percepção e de apreciação do real. O autor chama a atenção para o fato de que as variáveis, consoante as classes sociais ou meios intelectuais são produzidas pelas disposições estáveis e partilhadas, próprias do grupo. Desta forma, estariam sendo construídas representações do mundo social (CHARTIER, 1981 p. 116-17). A estas representações, Chartier (1981 p. 17) atribui várias características que são da maior importância para o estudo de quaisquer representações, como a sua propriedade de serem produzidas por um grupo e de determinarem poder.

Chartier faz também uma importante relação entre as representações e a identidade dos grupos, afirmando que ambas só existem para comandar atos ou ações:

(...) mesmo as representações coletivas mais elevadas só têm uma existência, isto é, só o são verdadeiramente, a partir do momento em que comandam atos - que tem por objetivo a construção do mundo social, e como tal a definição contraditória das identidades - tanto a dos outros como a sua." (CHARTIER, 1981 p. 18),

ou seja, as identidades se forjam a partir de representações construídas socialmente com um propósito específico.

Assim como Chartier, outros autores demonstram o importante elo entre representações e identidades. Tratando das representações relativas a um dado espaço não podemos deixar de tratar também da questão da identidade dos grupos que habitam o mesmo. Assim como as representações, as identidades são um sistema de significação socialmente atribuído e estas últimas estão estreitamente associadas

\footnotetext{
2 Tradução nossa.

URBANA, V.6, no 9, ago-dez, 2014 - Dossiê: Dimensões Simbólicas das Intervenções Urbanas CIEC/UNICAMP
} 
às primeiras (SILVA, 2000, p. 89), que dão suporte ao processo de diferenciação e, portanto, de construção de uma identidade (SILVA, 2000, p. 91).

Silva (2000, p. 76) trabalha os conceitos de identidade e diferença, numa perspectiva em que são mutuamente determinados e conformam um sistema em que a diferença estaria na origem, no ato ou processo de diferenciação para conformação da identidade. As identidades e as diferenças, ainda nesta perspectiva, "têm que ser ativamente produzidas. Elas não são criaturas do mundo natural ou de um mundo transcendental, mas do mundo cultural e social. (...) A identidade e a diferença são criações sociais e culturais." Como relação social, a identidade está sujeita a "vetores de força, a relações de poder", assim identidades e diferenças são impostas, elas são disputadas (SILVA, op. cit., p. 81).

Isso posto, verificar se os suburbanos produziram ou não representações e identidade sobre os Subúrbios e sua cidade, e quais representações e identidade foram estas, está no cerne da questão do seu lugar na disputa do poder em relação à Zona Sul, por exemplo. No caso, se houve uma construção social de representações e identidades, qual o grau de poder elas poderiam ter sobre o Estado para garantir-lhes acesso a melhoramentos e melhor qualidade de vida na cidade.

\section{Metodologia}

Relativamente às representações sobre o subúrbio produzidas fora do mesmo, foi consultado o trabalho de Cardoso (2009). Sobre as representações produzidas no próprio subúrbio, foram consultados 14 periódicos ${ }^{3}$, abrangendo um período de 1901 a 1941. A partir de uma primeira listagem de periódicos encontradas em um trabalho de Lamarão (2012), foram procurados periódicos sobre a área e em alguns deles foram encontradas referências a outros. Na bibliografia sobre subúrbio pesquisada também foram encontradas algumas referências a periódicos suburbanos (OLIVEIRA e FERNANDES, 2010).

A consulta à obra de Lima Barreto também serviu de fonte de pesquisa. Grande autor da literatura brasileira, Barreto também escreveu diversas crônicas sobre o Subúrbio que foram publicadas em jornais de grande circulação. Ele, morador do Subúrbio, foi porta-voz de representações sobre esta localidade que assim ganharam disseminação mais ampla.

\footnotetext{
${ }^{3}$ No final deste trabalho, relacionamos os periódicos consultados. A imprensa local chega, conforme a bibliografia, até a década de 1940. Deve-se ressaltar, entretanto, que as coleções estão muito falhas e que diversos periódicos locais dos quais tivemos notícias não foram encontrados ou estavam fora de consulta. Mas acreditamos que o material encontrado serve como uma boa amostragem "aleatória". URBANA, V.6, no 9, ago-dez, 2014 - Dossiê: Dimensões Simbólicas das Intervenções Urbanas CIEC/UNICAMP
} 
Com este material, pudemos empreender nosso trabalho que objetivava conhecer as representações e a identidade do Subúrbio carioca, na primeira metade do século $X X$.

\section{As representações sobre o Subúrbio}

\subsection{As representações "de fora"}

No já citado trabalho sobre a segregação sócio-espacial e a "invenção da Zona Sul" (CARDOSO, 2009), para o qual foi feita uma pesquisa em um jornal local e em periódicos de larga circulação, verificamos que as principais representações sobre aquela área eram de riqueza, beleza, saúde, sensualidade e modernidade, e eram muitas vezes contrapostas às características do Subúrbio num processo de diferenciação que era o primeiro passo para o estabelecimento de uma identidade. ${ }^{4}$

Numa época em que alguns bairros da Zona Sul, como Copacabana, Ipanema e Leblon, (aquém túneis ${ }^{5}$ ) ainda podiam ser considerados subúrbios, uma crônica publicada na edição de O Beira-Mar, jornal daquela Zona, de 7 de outubro de 1923, os moradores eram assim caracterizados:

(...) A vida aquem dos tunneis é sempre mais activa do que em qualquer outro bairro carioca. Nem é preciso indagar muito para chegar a uma tal conclusão. Copacabana é o sitio da saúde, por isso mesmo, o logar em que mais se nota a actividade vital. Quem percorre todos os arrabaldes occupados pelas famílias que bebem os ares desta encantadora Guanabara, estabelecendo um termo de comparação com o que tiver observado em Copacabana, verifica, desde logo, que o contraste é chocante. O aspecto geral topographico, o clima, os hábitos, os costumes, as construções, os trajes, são inteiramente diversos dos demais. Apenas o sotaque ainda não tomou feição própria mas parece que evolue para isso. Nos bondes, nos auto-amnibus, trazem todos na phisionaomia traços de quem vive uma vida sadia, sob um regimem de desporto e de boa alimentação. E com effeito, os médicos do Leme, da Egrejinha, de Ipanema e do Leblon já andam apavorados com a falta de clientes. O numero de clínicos é, evidentemente, maior do que o de clientes. (...) Emquanto nos subúrbios cada semana é marcada pela abertura de mais uma pharmacia, aqui muitas se fecham ou se transformam em perfumarias. É sem duvida porque Deus, o hygienisa maximo, zela pela saúde de Copacabana.

\footnotetext{
${ }^{4}$ Sobre a importância do processo de diferenciação para o estabelecimento de identidades, veja-se Silva, Tomaz Tadeu org. Identidade e diferença. A perspectiva dos estudos culturais. Petrópolis, Vozes, 2000.

${ }^{5}$ Alguns bairros da área que viria a ser chamada de Zona Sul, como Copacabana Ipanema e Leblon, se comunicavam com o restante da cidade através de túneis. Assim, para o jornal de bairro o "aquém túneis" é a própria área da Zona Sul.

URBANA, V.6, no 9, ago-dez, 2014 - Dossiê: Dimensões Simbólicas das Intervenções Urbanas CIEC/UNICAMP
} 
Embora esta crônica acima faça uma diferenciação dos moradores da Zona Sul de todos os demais da cidade, no final, é mais marcada esta diferenciação em relação ao Subúrbio. O Subúrbio se coloca aí como o extremo oposto da Zona Sul ${ }^{6}$.

Ainda sobre o processo de diferenciação de demais partes da cidade, principalmente dos "subúrbios", outra crônica do Beira Mar, datada de 11 de novembro de 1923 assim se referia aos motoristas de táxi que se faziam ponto em uma praça central do bairro de Copacabana:

Pela madrugada trazem os seus carros dos depositos, param no ponto, espalham a ferramenta pela calçada e começam a martelar, a soldar, a experimentar os motores, como se a Praça fosse sua oficina mecanica.

Ora, nem no Engenho de Dentro permitte-se tanta liberdade na via publica. Copacabana preciza de mais silencio e de mais conforto. Ella o merece.

Já nos bastam os estragos da feira das quartas que transformam o coração do bairro aristocrático em suburbio da Leopoldina. (...)

A grande imprensa, por sua vez, secundava os desejos de diferenciação da Zona Sul em relação ao Subúrbio. Como exemplo, mostraremos mais uma evidência da diversidade de representações para as diferentes áreas da cidade no artigo que recebeu o sugestivo título de "Dois mundos opostos", publicado em O Cruzeiro na edição de 3 de janeiro de 1953 :

Nos dois mundos antagônicos do Rio se forjaram dois estilos de vida totalmente diversos. Aqui não falamos, é claro, de meio termo, mas do que são, caracteristicamente, a 'zona sul' e a 'zona norte'. A zona sul, que começa propriamente no Flamengo, é a civilização do apartamento, e das praias maliciosas, do traje e dos hábitos esportivos, da 'boite' e do pecado à meialuz, dos enredos grã-finos, do 'pif-paf' de família, dos bonitões de músculos à mostra e dos suculentos brotinhos queimados de sol, dos conquistadores de alto coturno e de certas damas habitualmente conquistáveis, do 'short', do blusão e do 'slack', dos hotéis de luxo (e de outros de má reputação) e dos turistas ensolarados. O Rio cosmopolita está na zona sul, onde uma centena de nacionalidades se tropicalizam à beira das praias. A zona norte é Brasil $100 \%$. A gente mora largamente em casa (muitas vezes com quintal) e a casa impõe um sistema diferente de vida, patriarcal, conservador. Vizinhança tagarela e prestativa. Garotos brincando na calçada. Reuniões cordiais na sala de visitas. Solteironas ociosas e mocinhas sentimentais analizando a vida que passa debaixo das janelas. Namoro no portão, amor sob controle - para casar. Festinhas familiares, de fraca dosagem alcoólica. A permanente compostura no traje, ajustada com o do procedimento. Paletó e gravata. Mais 'toilette' que vestidos, mais área coberta nos corpos femininos. Vida mais barata.

\footnotetext{
${ }^{6}$ O termo Zona Sul foi lançado pelo Jornal Beira-Mar em 1923 e levaria ainda muitos anos a se consolidar como um topônimo ao contrário do termo Subúrbio que desde princípios do século XX, como afirmamos, já se consolidara como um topônimo.

URBANA, V.6, no 9, ago-dez, 2014 - Dossiê: Dimensões Simbólicas das Intervenções Urbanas CIEC/UNICAMP
} 
Empregada de 300 réis. Menos, água, mais calor. Diversão pouca, nada de 'boite' e 'night-clubs'. Noite vazia de pecados e de passos boêmios e sortilégios. Vida menos agradável aos homens, mais abençoada pelos santos. Zona sul- zona norte, paraíso e purgatório do Rio. Sair do purgatório e ganhar o paraíso é aspiração de quase todos, mas há quem prefira, sinceramente, a vida simples e provinciana dos bairros e subúrbios do norte. Para muitos a zona sul não é o paraíso, mas o inferno da perdição, onde Copacabana dita a imoralidade, o aviltamento dos costumes, a frivolidade e a boemia.

Essas representações sobre o Subúrbio vieram inclusive a, além de ajudar a cimentar a valorização da Zona Sul e o processo de auto-segregação das camadas de renda superiores aí, criar um enorme preconceito relativamente ao Subúrbio, seus moradores e quase tudo de que lá viesse, exceto, em alguns casos a música, como o samba. E ainda hoje este sentimento persiste, embora, com menos ênfase, apesar das significativas mudanças que lá vem ocorrendo.

\subsection{As representações "de dentro"}

Ao contrário da Zona Sul, o Subúrbio não fala muito de si mesmo em seus periódicos, criados, na maioria das vezes, para lutar por melhoramentos urbanos nesta área. Foram encontradas poucas crônicas com expressões que tentassem refletir uma imagem ou criar representação sobre a área ao contrário do que ocorreu com a pesquisa no jornal de bairro sobre a Zona Sul. Embora muitas matérias, em geral, pedissem melhoramentos, o que dava para caracterizar a precariedade da vida urbana na área, não se achava muito além disso, com exceções, é claro, que passaremos a mostrar.

Em princípios do século $X X$, a imprensa local referia-se frequentemente ao Subúrbio como a "infeliz zona" ou o "Matto-Grosso". De fato, estas expressões apareciam em matérias onde eram reivindicados diversos melhoramentos para os bairros situados naquela área, como, por exemplo: calçamento; iluminação; capinação, pois o mato grassava em várias ruas; irrigação, pois, à falta de calçamento, os bondes levantavam poeira quando passavam; abastecimento de água; transportes melhores etc. 7 Acredita-se, que estas representações, embora negativas, eram do interesse das populações locais, com o objetivo de chamar a atenção dos poderes públicos para a precariedade da cidade naquele local e cobrar-lhes

\footnotetext{
${ }^{7}$ Em nossa pesquisa sobre a Zona Sul também encontramos, duas vezes apenas referências onde o bairro de Leblon era chamado de infeliz devido à falta de melhoramentos que eram, nestas matérias, reivindicados. Este bairro estava ainda sendo incorporado à malha urbana da cidade na época e poderia ser considerado um autêntico subúrbio embora nunca tenha sido assim chamado.

URBANA, V.6, no 9, ago-dez, 2014 - Dossiê: Dimensões Simbólicas das Intervenções Urbanas CIEC/UNICAMP
} 
melhoramentos. Assim, embora em alguns casos fossem ressaltadas boas coisas da área, que era chamada de "pitoresca", os aspectos negativos muitas vezes estavam presentes nas mesmas matérias. Como vemos no texto a seguir, publicado em $\mathrm{O}$ Suburbio em 7 de setembro de 1907, que reclamava mais linhas de bondes para os bairros do Subúrbio:

(...) É talvez por falta de viação para todos os pontos seus, afastados da linha ferrea, que a zona suburbana encontra-se ainda em tão deplorável atrazo! Algumas de suas regiões mais pittorescas, achavam-se amesquinhadas por uma tal incúria, e tão enxovalhadas de lamaçaes, e tão comidas de mato bravo que lembram velhas regiões abandonadas, onde o homem parece não ter pisado!

E uma vez que a viação traga movimento e vida como há forçosamente trazer, a essas paragens mortas, que não parecem estar a poucos passos da Capital, e della fazem parte, mas estarem sumidas nos ínvios sertões de Mato Grosso; (...)

O centro da cidade já está civilisado. Pelo menos não é o botocudo que era há meia dúzia de annos apenas. É tempo de cuidar também dos pobres subúrbios, se não apodreceram já roídos pela gafieira, nos braços deprimentes do abandono, em que têm vegetado até agora, é porque são lavados pelos bons ares com que os bafeja a Natureza, essa excellente irmã de caridade, $(\ldots)$

Embora as representações de "infeliz zona" ou de "Mato-Grosso" sejam as mais encontradas nos jornais locais, também há outros termos negativos pelos quais se refere ao Subúrbio: "misera zona" e "pobres subúrbios" são alguns deles. Os jornais de maior circulação, por sua vez, secundavam os jornais locais, chamando-o daqueles termos como pode ser verificado em texto extraído da Gazeta de Notícias e publicado em O Suburbio de 24 de agosto de 1907, em que aquele grande jornal chama a área em foco de "Matto-Grosso":

O 70 número d'O Suburbio esta bom a valer. Variado e bem paginado, cheio de verve em suas secções humorísticas e com um magnífico attestado de administração financeira.

A trindade que o está dirigindo, está vencendo o Matto-Grosso do Distrito Federal, que bem merece os esforços e a boa vontade dos que estão à testa do bello semanário (...)

Apesar de predominarem representações negativas, também encontramos algumas representações positivas no início do século $X X$, em que a natureza e a tranquilidade são ressaltadas e contrapostas à vida agitada e ruidosa no

URBANA, V.6, no 9, ago-dez, 2014 - Dossiê: Dimensões Simbólicas das Intervenções Urbanas CIEC/UNICAMP 
"centro", como na crônica publicada em Progresso Suburbano em 16 de abril de 1902, intitulada "A vida nos Subúrbios":

É doce, bella e prazenteira, cheia de festas, risos e prazer a vida gozada no centro ruidoso de uma cidade populosa. Cada dia, cada instante, novos divertimentos, alegres passeitatas, pic-nics, jogos, corridas frontões, bellodromos, tudo isso alegra a mocidade, encanta o espírito e amenisa a vida, ou do pacato burguez urbano ou do perdulário inconsciente.

(...)

Quão differente é a vida nos sububrios! Longe do ruído ensurdecedor que endoudece, gozando de um silencio que deleita, sente-se na alma um prazer infindo. Sob a abóboda cerula de um ceo sempre sereno gozando a brisa suave, que, mansamente, vemos e apreciamos as verdadeiras maravilhas da natureza.

Espessas mattas de arvores gigantescas desenrolam-se ás nossas vistas e suas grimpas parecem querer tocar no firmamento, onde procuram abrigo as pequenas aves canoras, que nos arrebatam com suas melodias e trinados maviosos.

Nada de palácios sumptuosos, humildes casas alegres e arejadas, sob a forma elegante de chalet destacam-se na sua maioria. Ao cahir da tarde, passeiam alegres e risonhas, de braços com suas amigas e collegas, elegantes senhoritas, vestidas com tanta simplicidade que encanta. Divertem-se as creanças, em plena rua, com jogos infantis.

Recostados em respeitáveis poltronas, palestram os velhos progenitores, divisando-se em seus semblantes o gozo e a satisfação.

(...)

Eis, o que é a vida na cidade: incommodos, empurrões, furtos e desgostos, nos theatros; nos outros logares de divertimento não fallávamos, pois são tantos inconvenientes que o nosso artigo não comporta enumeral-os. A vida nos subúrbios é mais tranquilla, mais suave e talvez mais amorosa, poética e duradoura; tanto é que applicarei aos subúrbios o que o nosso grande poeta dizia:

'Nossos boques têm mais vida, Nossa vida mais amores'.

Tantas representações positivas de beleza, quietude, elegância, belezas das mulheres, nos fazem lembrar as representações que eram muitíssimo disseminadas sobre a Zona Sul na primeira metade do século XX, (CARDOSO, 2009) mas no Subúrbio elas são raras, embora apareçam. Nesta crônica também podemos perceber um processo de identificação, com essas representações, pela diferença com o "centro" da cidade: ruidoso, perigoso etc. Esta crônica também poderia se chamar como aquela já citada "Os dois mundos opostos". Verifica-se que o subúrbio também veiculava representações positivas opostas ao restante da cidade, perfazendo uma dicotomia. Um aspecto do Subúrbio que era mais ressaltado positivamente era o seu 
comércio, como vemos na matéria intitulada "A vida nos subúrbio", publicada em Progresso Suburbano em 2 de março de 1902:

Rápido e bem rápido tem sido há uns anos para cá o desenvolvimento dos subúrbios. A população tem crescido de uma maneira extraordinária; o commercio tem se espalhado e desenvolvido consideravelmente levando a vida e a animação em todo logar onde tem penetrado (...)

Foi encontrado um texto que, reclamando melhoramentos para a área, dá conta da pobreza existente ali e da precariedade da vida urbana no Subúrbio nas primeiras décadas de século XX, como a crônica intitulada "Em ar de conversa", publicada na Gazeta Suburbana em 8 de setembro de 1910:

(...) Muitos dizem que os moradores de subúrbios são pobres, e portanto não carecem de luxo. (...) Pelo facto de sermos pobres não quer dizer que temos a obrigação de andarmos em atoleiros enchendo o calçado de lama; o facto de sermos pobres não quer dizer que temos obrigação de expôr nossa vida cada vez que tenhamos de sahir á rua; por sermos pobres não somos obrigados, quando um bond nos quebra uma perna, a gemer durante três ou quatro horas até que alguem nos venha apanhar; por sermos pobres não somos obrigados a correr com bacias de água quando nossa casa, por descuido da cosinheira, pega fogo (...)

No jornal O Commercio Suburbano de 15 de julho de 1911, ficamos sabendo da preferência dos moradores do Subúrbio pelo comércio de fora da área, fato contra o qual o jornal reclama veementemente porque o comércio da área havia crescido muito recentemente. O texto trata até mesmo do preconceito dos suburbanos em relação aos próprios Subúrbios.Vejamos:

A falta de união do povo suburbano, analysada em nosso ultimo numero, leva-nos a tratar de um outro assumpto de maxima importância.

Os suburbanos não tem amor aos subúrbios, não tem o chamado 'bairrismo', o gosto pelo logar onde residem. (...)

De facto o povo suburbano, por espírito de economia fantástica e por um preconceito injustificado faz a maior parte de suas compras no centro da cidade, quando poderia fazel-as quase a dois passos de casa." (...)

Algumas matérias, anos mais tarde, porém, davam conta de uma vida elegante no Subúrbio, como a coluna sobre o "Footing" publicada na Revista Suburbana em 3 de setembro de 1922:

A nossa sociedade elegante tem o footing como objeto indispensável á vida.

URBANA, V.6, no 9, ago-dez, 2014 - Dossiê: Dimensões Simbólicas das Intervenções Urbanas CIEC/UNICAMP 
Hoje em dia não é só no Flamengo, nas Avenidas da Capital da República, que se cultiva esse Sport.

Percorrendo mais longínquos bairros de nossa cidade, quer dizer, estendendo as nossas vistas para os subúrbios, vemos que o elegante passeio, é frequentado com maior assiduidade que a imaginação humana pode conceber!

É ver aos domingos essa Praça Saens Peña, o jardim do Meyer e outras localidades suburbanas, onde encantadoras 'jeaunnes filles' passando, iniciam os seus 'flirts' e com a diversidade de suas 'toilettes' imprimem um aspecto soberbo ás alamedas ajardinadas daquelas paragens. (...)

No mesmo número da Revista Suburbana, encontramos uma interessante crônica sobre o bairro suburbano da Méier, intitulada "O Meyer por dentro", que ressalta aspectos de elegância e modernidade no Subúrbio:

Indiscutivelmente é o nosso querido Meyer a capital da zona suburbana. Para tal sobram-Ihe predicados altamente dignos de referencia. Tem vida própria, independente, á parte, pois que nada lhe falta e, ao contrario, tudo lhe chega em escala natural é hora psychologica das necessidades inadiáveis. Poder-se ia aqui viver dez ou mais annos sem ir á Avenida, que no curso normal da nossa vida jamais deixaria de ver esse rythmo perpetuo de todos os dias.

(...)

Tem sua vida diurna rumorosa e febril com seus pregoeiros de mil e um negócios. Á noite sua aristocracia, sua existência social e elegante, como pedra rara de mil facetas luminosas, fulge adejando no jardim ou brilha á porta de Cine-Meyer, do Mascotte ou, ainda, no Theatro Polytheama

Que delicia para os olhos e deleite de espírito ver-se aos domingos todo o seu incomparável mundo feminino, como num corso feérico passeando no Jardim, conglobando-se á entrada dos cinemas, assaltando os bondes para o futebol ou comprando a sorte no Mafuá depois de mysticas orações na Igreja da rua Cardoso!

O Meyer é, outrossim, o paraíso dos namorados. (...)

Os pontos predilectos ás lutas de cupido varia á proporção do fogo que thes queima na alma refinando-lhes gostos esquisitos de corações volúveis, romanticamente felizes. Ou nos toscos bancos do jardim sob a luz diaphana e velada dos abat-jours, ou á hora sussurante de entrada nos cinemas, no fecha-fécha dos apertos, com a campainha tilitando, ou então na escadaria da ponte mais em moda agora, sob a benção do luar, que, do alto dessora o póllen luminoso fri (sic) da sua cumplicidade. Como a Dança de São Guido que nos bóle com todos os nervos e nos provoca as mais sesuaes contrações, tudo aqui namora, todos caem no flirt - velhos e moças, viúvas e casadas, feias e bllas...

Uma delicia, o flirt no Meyer.

Embora em texto já citado, se apresente uma imagem positiva dos "chalets", principal estilo arquitetônico existente no Subúrbio à época, anos depois as 
construções desta área são duramente criticadas, por enfeiarem o local, como aparece na Revista Suburnana de 26 de setembro de 1922:

A construção nos subúrbios se ressente de uma lamentável fealdade e de uma total incongruencia com o local. As casas não são construídas com o aspecto de gracis casas de subúrbios, garridas e louçãs. São hediondos, soturnos e pesadíssimos monstrengos, sem caráter próprio e relação com o local; verdadeiros paralelepípedos de alvenaria, com um puxadito no fundo e uma varanda ao lado, compoteiras na cimalha e um horrendo portão com mezzaninos, tendo grades de cadêa. Quando não são desse typo, são os velhos 'chalets' que hoje estão fora de moda, e foram substituídos pelos taes paralelepípedos de alvenaria de tijolos em cuja fachada se ostenta uma (ilegível) de villa europeia.

(...)

Os particulares que dispõem de posses, deviam ter jardins floridos e amplos, o que modificaria o insólito aspecto urbano que actualmente têm os nossos subúrbios - cousa que não se espera topar em paragens de tal nome. (...)

Nesta citação, vê-se como o Subúrbio carecia de referências próprias de subúrbio, pois, em realidade, já não o era mais. Isso dificulta o processo de identificação positiva.

$\mathrm{Na}$ Revista Suburbana de fevereiro de $1933^{\circ}$, uma matéria intitulada "O Suburbio Abandonado" pede vários melhoramentos para o Subúrbio que era carente de saneamento, pavimentação, escolas, meios de transportes etc. Esta mesma matéria, chama diversos bairros do Subúrbio de cidades devido ao grande aumento de sua população e ao desenvolvimento de seu comércio, demonstrando aí uma contradição com o fato de se chamarem de Subúrbios:

(...) Infelizmente, os dirigentes municipaes, preocupados com 0 embellezamento da zona urbana, talvez por ser esta mais atingida pelos olhares curiosos e não raro maliciosos dos estrangeiros que aqui aportam em busca de sensações mais ou menos extravagantes, pouca ou nenhuma atenção têm dispensado aos subúrbios. Resulta dahi que grandes cidades como Meyer, Engenho de Dentro, Cascadura, Madureira, Jacarepagua, Ramos, Penha, Braz de Pina etc. estejam a míngua de favores officiaes, entregues inteiramente aos próprios recursos, vivendo quase que exclusivamente da iniciativa particular.

(...)

É á iniciativa particular que os subúrbios agradecem a existência do seu commercio activo, o numero considerável de verdadeiros empórios commerciaes, estabelecimentos que fariam figura em qualquer das ruas centrais da nossa formosa urbs. (...)

\footnotetext{
${ }^{8}$ Esta revista surgiu em 1918 e desapareceu em 1922. Nesta fase era semanal. Depois voltou novamente em 1933, com periodicidade mensal, mas não durou muito tempo.

URBANA, V.6, no 9, ago-dez, 2014 - Dossiê: Dimensões Simbólicas das Intervenções Urbanas CIEC/UNICAMP
} 
É interessante notar nestas passagens o grau de "crise de identidade" que existia no Subúrbio na época. Embora não se questionasse que esta parte da cidade fosse um subúrbio, não se reconheciam ali as características de um subúrbio, pois não o era mais mesmo, apesar de assim ser chamado. Estava totalmente ocupado e mantinha relações constantes com o centro

É ainda interessante notar que os outros bairros fora do Subúrbio eram chamados de arrabaldes ou bairros, como se pode ver na seguinte passagem da Revista Suburbana julho de 1919: "O desvio das rendas dos subúrbios que é criminosamente applicado em obras sumptuosas nos bairros chics e aristocráticos da cidade, emquanto a zona suburbana precisa de melhoramentos uteis e necessários."

Ou como no exemplo a seguir, da Gazeta Suburbana de 8 de setembro de 1910: "(...) emquanto a renda da Prefeitura é empregada em melhoramentos na zona urbana e dos arrabaldes chics, os subúrbios vivem no mais completo abandono.(...)" Embora apareçam textos dando conta de aspectos elegantes do Subúrbio, ele, de fato, se diferencia dos bairros chics, uma contradição generalizada. E nesta época vários bairros da região que futuramente seria chamada de Zona Sul, ainda tinham características suburbanas. Mas eram chamados de arrabaldes chics ou bairros aristocráticos. Estes, em contraste com o Subúrbio, eram chamados de "bairros felizes" (Almanack Suburbano, 1911). Somente em 1933 há um questionamento sobre o fato de alguns bairros se chamarem subúrbios, como se vê na Revista Suburbana de maio de 1933:

(...) Além disso há de notar o modo differente porque sempre foram tratados os bairros em virtude mesmo da diversidade de classificação que se lhes dá: uns são chamados bairros, outros subúrbios.

Aquelles sempre merecem os desvelos dos administradores: estes jamais conseguiram siquer despertar-Ihes a atenção. (...)

Esta "crise de identidade" dos subúrbios, verificada nos jornais locais, vem exemplificar e corroborar o que Fernandes (2011) chamou de rapto ideológico da categoria subúrbio, ou seja, a categoria sendo empregada fora de seu sentido de origem, apenas para desqualificar os moradores desta área que em sua maioria eram pobres.

É no Almanaque Suburbano de 1941, organizado por H. Dias da Cruz que encontramos várias representações positivas sobre o Subúrbio. O autor vai dando uma nota e um pequeno histórico para cada bairro. Sendo uma publicação para URBANA, V.6, no 9, ago-dez, 2014 - Dossiê: Dimensões Simbólicas das Intervenções Urbanas CIEC/UNICAMP 
divulgar o Subúrbio, não é de admirar que contenha diversas representações positivas. Este é o caso do seguinte texto: "(...) Do Rocha ao Riachuelo o elétrico vai num minuto. 600 metros. Vida social elegante, movimentada, como movimentado o comercio. Ruas bem pavimentadas. Predios de linhas modernas. (...)"

Sobre Todos os Santos, o Almanaque Suburbano afirma: " Magnifico ponto residencial pela sua quietude." Sobre Cascadura, levanta aspectos positivos e negativos: "Vemos, mesmo, ainda, enfeiando as suas ruas principais, ladeando prédios esplendidos e lojas bem montadas, casebres que estão gritando por picareta." Sobre Ramos, dá as seguintes informações:

Ramos é um subúrbio elegante. Suas vias publicas são todas longas e bem cuidadas. A impressão que logo se sente, deixando o trem, é a mais agradável. Ramos, como se sabe, disfruta o conforto de uma praia de banhos. Dos Suburbios da Leopoldina foi dos primeiros a receber benefícios públicos. Uma após outras, esplendidas ruas com cuidada prediação. Toda a área está habitada até mesmo a parte do mar, partindo de ambos os lados das linhas, os mesmos caminhos que formam bom sistema de comunicação. As ruas paralelas á estação são todas ocupadas por casas comerciais bem postas. (...)

A matéria apresenta ainda duas fotos de banhistas na praia de Ramos. Em uma estão com roupas de banho e em outra estão vestidos. Na legenda, lê-se: "Bela praia que é bem a 'Copacabana dos Suburbios."' A seguir, afirma que esta praia é bem frequentada e merece melhoramentos pois "só tem o que a Natureza lhe deu."

Aqueles são alguns dos exemplos que tiramos do Almanaque Suburbano, mas, para não ficar demasiadamente repetitivo só citamos estes exemplos. De uma maneira geral, indo bairro a bairro, que chama de verdadeiras "cidades", aquela publicação procura ressaltar o que há de melhor em cada bairro e faz algumas críticas ao estado de outros. Sobre Engenho de Dentro e Bangu, ressalta sua função fabril, chamando-os de bairros proletários. Já outros são eminentemente residenciais e com comercio ativo. Aliás, o comércio é sempre destacado como sinal de progresso dos bairros "suburbanos". Além desta parte descritiva sobre os bairros, o Almanaque, como é de se esperar, apresenta uma série de informações úteis para os moradores do Subúrbio.

As representações veiculadas pela imprensa local, ao longo dos anos foram divergentes. Ao mesmo tempo em que algumas matérias de periódicos apresentavam crônicas com imagens positivas, inclusive descrevendo a elegância do "footing" no Méier, comparável ao do Flamengo, bairro da Zona Sul (Revista Suburbana, 3 de setembro de 1922), outras veiculavam representações negativas, como vimos acima. URBANA, V.6, no 9, ago-dez, 2014 - Dossiê: Dimensões Simbólicas das Intervenções Urbanas CIEC/UNICAMP 
Na obra publicada em crônicas de Lima Barreto, a situação não é diferente. Tanto se veiculam representações positivas quanto representações negativas sobre o Subúrbio. Tomando como base 11 crônicas sobre o Subúrbio, listadas na obra de organizada por Resende e Valença (2004), o tema que mais aparece em crônicas do autor sobre a área é o péssimo calçamento dos caminhos que levam ao cemitério de Inhaúma, repetidamente causando a queda do caixão, como em História Macabra, publicada na revista Careta em 17/7/1915; Queixa de Defunto, publicada na mesma revista em 27/3/1920; e Os enterros em Inhaúma, também publicada na Careta em 26/8/1922. Nesta última também comenta que, devido à pobreza de seus moradores, os caixões com os defuntos são levados até o cemitério nas mãos, e que às vezes os pesarosos amigos dos que são enterrados tem que passar por lodaçais.

Na crônica Feiras Livres, publicada na revista Careta em 16/7/1921, o autor passa ideias positivas e negativas sobre o subúrbio. As positivas ficam por conta da beleza das senhoras e moças que frequentam a feira, sobre as quais ele afirma: "Nunca as vi tão lindas nem mesmo na Rua do Ouvidor que frequento desde os dezesseis anos quando me matriculei na Escola Politécnica." O aspecto negativo que ressalta nesta crônica é a existência de vagabundos brigões no Subúrbio: "Esse vagabundozinho dos subúrbios é um tipo lá daquelas bandas que a gente não sabe como vive. Toma uns ares de valentão e não faz nada."

$\mathrm{Na}$ crônica intitulada $A$ estação, publicada na Gazeta de Notícias de 6/10/1921, Lima Barreto ressalta aspectos positivos do Subúrbio, particularmente do bairro do Méier que, por ser o entroncamento de várias linhas de bondes e do trem, "a impressão que dá não é bem de subúrbio, mas de uma cidade média" Sobre o Méier, faz ainda uma descrição bastante positiva em alguns aspectos e nem tanto em outros, nesta mesma crônica:

(...) É o Méier o orgulho dos subúrbios e dos suburbanos. Tem confeitarias decentes, botequins freqüentados; tem padarias que fabricam pães, estimados e procurados; tem dois cinemas, um dos quais funciona em casa edificada adrede; tem circo-teatro, tosco, mais tem; tem casas de jogo patenteadas e garantidas pela virtude, nunca posta em dúvida, do Estado, e boêmios, um tanto de segunda mão; e outras perfeições urbanas, quer honestas quer desonestas.

As casas de moda pois as há também, e de algum aparato, possuem nomes chics, ao gosto da Rua do Ouvidor (...)

Na crônica $O$ cedro de Teresópolis, Lima Barreto dá informações contraditórias sobre o ajardinamento das casas do Subúrbio. A princípio afirma: "Os nossos URBANA, V.6, no 9, ago-dez, 2014 - Dossiê: Dimensões Simbólicas das Intervenções Urbanas CIEC/UNICAMP 
arrabaldes e subúrbios $^{9}$ são uma desolação. As casas de gente abastada têm, quando muito um jardinzito liliputiano de polegada e meia; e as da gente pobre não têm coisa alguma." Já na pagina seguinte trata do aspecto ainda roceiro da área:

Onde estão os jasmineiros das cercas? Onde estão aqueles extensos tapumes de maricás que se tornam de algodão que mais é neve, em pleno estio? Os subúrbios e arredores do Rio guardam dessas belas coisas roceiras, destroços como recordações.

Lima Barreto tratou ainda dos moradores do Subúrbio que em sua maioria eram pequenos funcionários públicos e que no Subúrbio eram arrogantes e se sentiam importantes mas "Chegam na rua do Ouvidor, desaparecem" como afirma na crônica O trem de subúrbios, publicada na Gazeta de Notícias em 21/12/1921. Na mesma crônica, dá impressões positivas, embora sarcásticas, sobre a vestimenta das mulheres que usam os trens à tarde: "Os vestuários, com raras exceções, são exageradíssimos. Botafogo e Petrópolis exageram Paris; e o subúrbio exagera aqueles dois centros de elegância."

Em outras crônicas, não são veiculadas representações nem positivas nem negativas. Entretanto, podemos concluir sobre os textos citados acima que o autor também, assim como os jornais locais, contribuiu para que fossem criadas representações divergentes sobre o Subúrbio.

\section{Considerações finais}

Como pudemos verificar, as publicações do Subúrbio e as crônicas de Lima Barreto, criaram e veicularam representações tanto positivas quanto negativas sobre a área em foco, cada uma "anulando" a outra. Este fato de não terem sido criadas representações coesas que dessem conta da imagem do lugar, deu oportunidade a que outras representações, muitas vezes ideológicas, produzidas fora, tomassem o lugar de representações hegemônicas. Isso se deve também, em parte, à grande diversidade de aspectos dos bairros que compunham o chamado Subúrbio.

Enquanto, com grande frequência eram atribuídas à Zona Sul na imprensa de bairro ou na grande imprensa, características como riqueza, beleza, felicidade, saúde, bairros chics, bairros aristocráticos, modernidade e cosmopolitismo, por exemplo (CARDOSO 2009), nossa pesquisa encontrou relacionadas ao Subúrbio uma

\footnotetext{
${ }^{9}$ É interessante notar a diferenciação que o autor faz entre os arrabaldes e os subúrbios. Aqueles, provavelmente também eram bairros que poderiam ser chamados de subúrbios, mas devido a sua ocupação por classes mais abastadas, eram chamados de arrabaldes.

URBANA, V.6, no 9, ago-dez, 2014 - Dossiê: Dimensões Simbólicas das Intervenções Urbanas CIEC/UNICAMP
} 
predominância de características negativas como pobreza, fealdade, infelicidade, insalubridade, bairros proletários, conservadorismo e provincianismo, por exemplo. De fato foram sublinhadas algumas características positivas deste lugar, mas a predominância era de características negativas.

No final da década de 1950, Soares (1960-p.197-198) ainda afirma que : "A palavra 'subúrbio' contém indubitavelmente na linguagem carioca um certo sentido depreciativo, que inclui não só uma ideia de recursos financeiros mais limitados, mas também um certo gênero de vida peculiar". Neste gênero de vida peculiar estavam sendo considerados a criação de galinhas e o cultivo de jardins, por exemplo.

Tendo o Subúrbio esta dificuldade de produzir representações coesas, ficou também prejudicado o processo de criação de uma identidade. Como afirma Silva (2000, p. 91) "É também por meio da representação que a identidade e a diferença se ligam a sistemas de poder. Quem tem o poder de representar tem o poder de definir e determinar a identidade." A falta de uma identidade, por sua vez, leva à perda do poder de se fazer valer e, por isso, a área chamada de Subúrbio sempre esteve mal atendida pelos poderes públicos, relativamente a outras áreas. Assim, em fins da primeira metade do século $X X$, já se haviam consolidado representações de "mundos opostos" entre Zona Sul e Subúrbio, que eram bem mais favoráveis á primeira área, como pudemos ver. Essa representação de "mundos opostos" parece ter se solidificado com o passar dos anos e só recentemente parece mudar, quando os antigos "subúrbios" passaram a ser chamados também de Zona Norte.

\section{Referências}

\subsection{Bibliografia}

CARDOSO, Elizabeth D. (2009). Segregação sócio-espacial e a invenção da Zona Sul carioca. 1920-1960. Tese de Doutorado. Niterói: Programa de Pós-Graduação em Geografia da UFF.

CHARTIER, Roger (1981). História cultural: entre práticas e representações. RJ: Bertran.

FERNANDES, Nelson da N. (2011). O rapto ideológico da categoria subúrbio. Rio de Janeiro. 1858-1945. Rio de Janeiro: Apicuri.

FERNANDEZ, Anelise C. F. (1996). "Assim é o meu subúrbio": o projeto de dignificação dos subúrbios entre as camadas médias suburbanas de 1948 a 1957. Dissertação de mestrado. Programa de Pó-Graduação em Sociologia/ UFRJ.

URBANA, V.6, no 9, ago-dez, 2014 - Dossiê: Dimensões Simbólicas das Intervenções Urbanas CIEC/UNICAMP 
LAMARÃO, Sergio T. de N. (2012). As revistas como fonte para a história da cidade do Rio de Janeiro. Revista do Arquivo Geral da Cidade do Rio de Janeiro, N. 6.

LEFEBVRE, Henri (1983). La presencia y la ausência. Contribucion a la teoria de lãs representaciones. . México: Fonde de Cultura Econômica.

LOBO, Dácio (2000). Representações sociais da escola pública. Tese de Doutorado. Fac. Educ./UFRJ.

MOSCOVICI, Serge (2012). Representações Sociais. Investigações em psicologia social. Petrópolis: Vozes.

OliveIRA, Marcio P. e FERNANDES, Nelson da N.(orgs.) (2010). 150 anos de subúrbio carioca. Rio de Janeiro: Lamparina: Faperj: EdUFF.

PEREIRA, Margareth da S. (2010). Subúrbio. In: Topalov, Christian et alli (org) Les ventures des mots de la ville a travers les temps, les languages et les sociétés. Paris: Ed. Robert Lafont, col Bouquins p. 1201-1206.

RESENDE, Beatriz e VALENÇA, Rachel (orgs.) (2004). Tôda Crônica- Lima Barreto. Rio de Janeiro,: AGIR.

SILVA, Tomaz Tadeu (org) (2000). Identidade e Diferença. A perspectiva dos Estudos Culturais. Petrópolis: Vozes.

SOARES, Maria Therezinha S. (1958-1959-1960) Divisões principais e limites externos do Grande Rio de Janeiro. In: Anais da Associação dos Geógrafos Brasileiros, vol. XII. São Paulo: A.G.B.

\subsection{Periódicos}

O Echo Suburbano (1901)

Progresso Suburbano (1902)

Commercio suburbano (1902)

O Suburbio (1907-1908)

O Condor (1908)

O Santacruzense (1908-1909)

Gazeta Suburbana (1910-1912)

O Santa Cruz (1911)

Almanack Suburbano (1911-1912)

Archivo Suburbano (1920)

O Scenario (1929)

Revista Suburbana (1918-1922; 1933)

O Suburbano (1935; 1940-1941)

Almanaque Suburbano (1941)

URBANA, V.6, no 9, ago-dez, 2014 - Dossiê: Dimensões Simbólicas das Intervenções Urbanas CIEC/UNICAMP 